\title{
Physalins B and F, seco-steroids isolated from Physalis angulata L., strongly inhibit proliferation, ultrastructure and infectivity of Trypanosoma cruzi
}

\author{
CÁSSIO S. MEIRA ${ }^{1}$, ELISALVA T. GUIMARÃES ${ }^{1,2}$, TANIRA M. BASTOS ${ }^{1}$, DIOGO R. M. \\ MOREIRA ${ }^{1}$, THEREZINHA C. B. TOMASSINI ${ }^{3}$, IVONE M. RIBEIRO ${ }^{3}$, RICARDO R. DOS \\ $\mathrm{SANTOS}^{4}$ and MILENA B. P. SOARES ${ }^{1,4} *$ \\ ${ }^{1}$ Fundação Oswaldo Cruz, Centro de Pesquisas Gonçalo Moniz, Rua Waldemar Falcão, 121, Candeal, Salvador, Bahia, \\ CEP: 40296-710, Brazil \\ ${ }^{2}$ Departamento de Ciências da Vida, Universidade do Estado da Bahia, Rua Silveira Martins, 2555, Cabula, Salvador, \\ Bahia, CEP: 41150-000, Brazil \\ ${ }^{3}$ Fundação Oswaldo Cruz, Instituto de Tecnologia em Fármacos (Farmanguinhos), Avenida Comandante Guaranys, \\ Facarepaguá, Rio de Faneiro, RF, CEP: 22775-903, Brazil \\ ${ }^{4}$ Hospital São Rafael, Centro de Biotecnologia e Terapia Celular, Avenida São Rafael, São Marcos, Salvador, Bahia, \\ CEP: 41253-190, Brazil
}

(Received 6 April 2013; revised 5 Fune 2013; accepted 1 Fuly 2013; first published online 4 September 2013)

\section{S U M MAR Y}

We previously observed that physalins have immunomodulatory properties, as well as antileishmanial and antiplasmodial activities. Here, we investigated the anti-Trypanosoma cruzi activity of physalins B, D, F and G. We found that physalins $\mathrm{B}$ and $\mathrm{F}$ were the most potent compounds against trypomastigote and epimastigote forms of T. cruzi. Electron microscopy of trypomastigotes incubated with physalin B showed disruption of kinetoplast, alterations in Golgi apparatus and endoplasmic reticulum, followed by the formation of myelin-like figures, which were stained with MDC to confirm their autophagic vacuole identity. Physalin B-mediated alteration in Golgi apparatus was likely due to T. cruzi protease perturbation; however physalins did not inhibit activity of the trypanosomal protease cruzain. Flow cytometry examination showed that cell death is mainly caused by necrosis. Treatment with physalins reduced the invasion process, as well as intracellular parasite development in macrophage cell culture, with a potency similar to benznidazole. We observed that a combination of physalins and benznidazole has a greater anti-T. cruzi activity than when compounds were used alone. These results indicate that physalins, specifically $\mathrm{B}$ and $\mathrm{F}$, are potent and selective trypanocidal agents. They cause structural alterations and induce autophagy, which ultimately lead to parasite cell death by a necrotic process.

Key words: Chagas disease, Trypanosoma cruzi, autophagy, seco-steroids, physalins.

\section{INTRODUCTION}

Chagas disease, caused by the haemoflagellate protozoan Trypanosoma cruzi, continues to affects millions of people in Latin America (Pinto-Dias, 2006). Subjects are infected by fecal matter contact of the insect vector (Hemiptera: Reduviidae), but blood transfusion, congenital transmission and ingestion of contaminated food also cause infection (Moncayo and Silveira, 2009). In the human host, infection is characterized by an acute phase followed by a chronic phase, in which cardiac, digestive or neurological disruptions develop (Coura and Castro, 2002).

There is no effective treatment once an individual has been infected with T. cruzi, and vaccine development is still in the experimental stage (Maya et al. 2007; Gupta et al. 2013). Chagas disease treatment is

* Corresponding author. Fundação Oswaldo Cruz, Centro de Pesquisas Gonçalo Moniz. Rua Waldemar Falcão, 121, Candeal, Salvador, Bahia, 40296-710, Brazil. E-mail: milena@bahia.fiocruz.br based on the use of benznidazole, a drug with limited use due to its toxicity and minimal benefits during the chronic phase of infection (Urbina and Docampo, 2003; Moreno et al. 2010). Currently, Chagas disease has only two pharmaceutical interventions available in clinical trials. Of these, the most advanced is the antifungal posaconazole, which targets parasite sterol synthesis and is undergoing phase II study (Moton et al. 2009; Urbina, 2010). The other is the K11777, a peptide which inhibits protease activity, which is in phase I study (Sajid et al. 2011). Therefore, it is clear that more pharmaceutical options must be developed to improve treatment.

Physalis angulata L. (Solanaceae) is an annual herb widely distributed in tropical and subtropical regions. It is rich in steroid compounds, such as physalins and withanolides. Physalins are a group of seco-steroids found in stem extracts of many Physalis species (Magalhães et al. 2006; Damu et al. 2007; Jin et al. 2012). Because of the chemical similarity with the glucocorticoid class of steroids, physalins are 

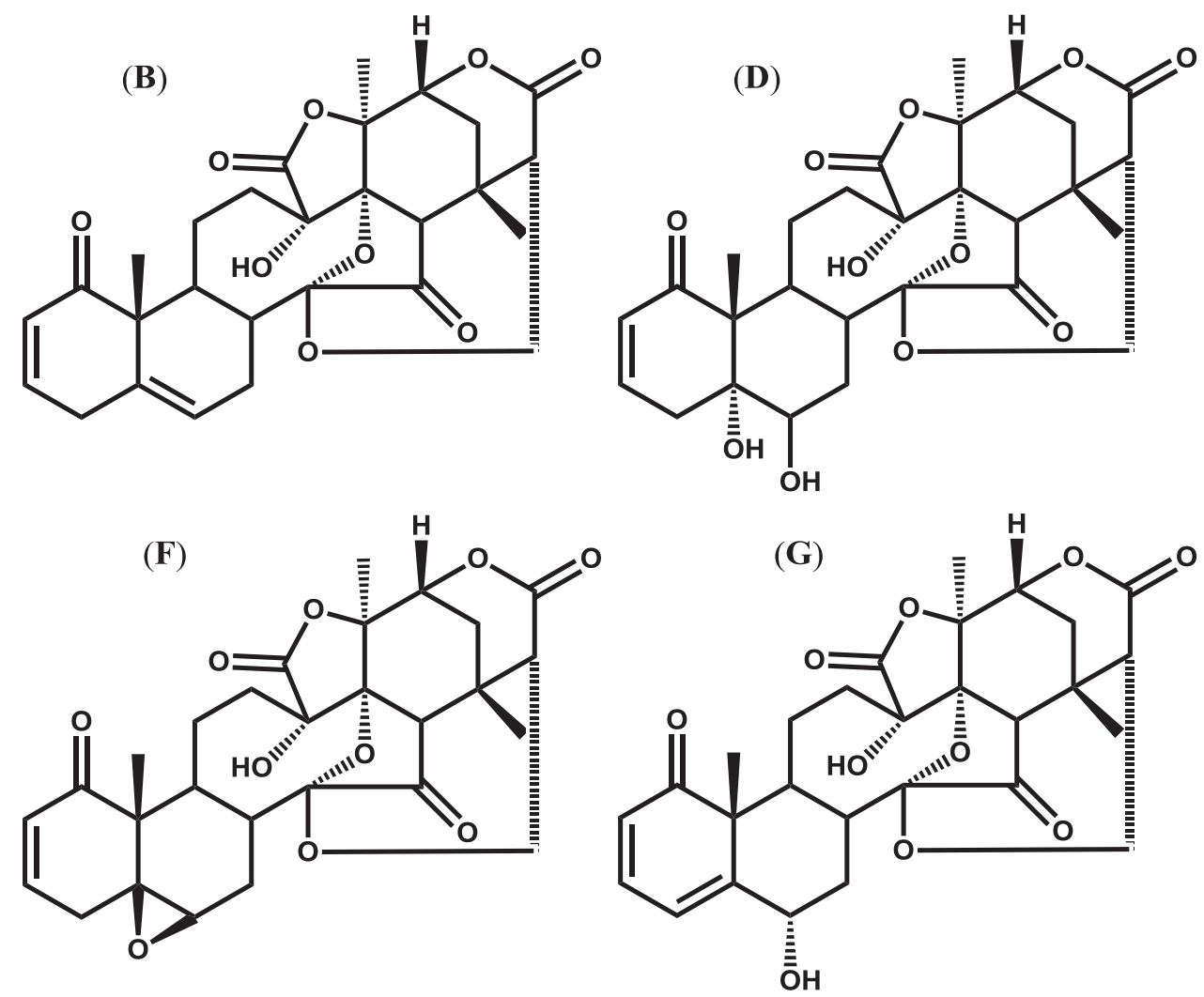

Fig. 1. Structures of physalins B, D, F and G.

well-known anti-inflammatory and immunosuppressant agents (Soares et al. 2003, 2006; JacoboHerrera et al. 2006). These compounds regulate many cellular activities, such as differentiation, proliferation, necrosis and apoptosis, adhesion and migration (Brustolim et al. 2010; Wu et al. 2012; Reyes-Reyes et al. 2013). Based on this, these compounds have been tested for anticancer activity and as inhibitors of pathogenic microbes (Chiang et al. 1992; Januário et al. 2002; Reyes-Reyes et al. 2013). Specifically, we observed that physalins B and $\mathrm{F}$ inhibit Leishmania major and Leishmania amazonensis infection in macrophages and mice (Guimarães et al. 2009). We also determined the antimalarial activity of physalins (Sá et al. 2011). Interestingly, we found that physalin D reduced blood parasitaemia in Plasmodium berghei-infected mice, while physalin $\mathrm{F}$ increased parasite load, possibly due to murine immune response interference.

Regarding the anti-T. cruzi activity of physalins, it was previously described that they inhibit epimastigote proliferation in axenic media, as well as in T. cruzi-infected triatomines (Vieira et al. 2008; Castro et al. 2009, 2012). The findings suggest physalins are useful compounds for vector-borne transmission control. Here, we report the activity of physalins B, D, F and G (Fig. 1) against bloodstream trypomastigotes, which is the infectious form in humans. After physalin treatment, we examined ultrastructural alteration and parasite death. Next, the activity of physalins $\mathrm{B}$ and $\mathrm{F}$ to inhibit the parasite invasion and development in macrophage cell culture was determined.

\section{MATERIALS AND METHODS}

\section{Drugs}

Physalins B, D, F and G were isolated from Physalis angulate L. Plants were collected in Belém do Pará (Brazil) and processed as previously described (Soares et al. 2003). Preparations of physalins B, D, $\mathrm{F}$ and $\mathrm{G}(96,95 \cdot 6,97 \cdot 8$ and $95 \%$ purity by HPLC, respectively) were dissolved in DMSO and diluted in culture medium for use in the assays. Benznidazole (LAFEPE, Recife, Brazil) was used as a positive control for the anti-T. cruzi assays. Amphotericin B (Gibco Laboratories, Gaithersburg, USA) was used as a positive control in the invasion assay. Gentian violet (Synth, São Paulo, Brazil) was used as a reference drug in the cytotoxicity assays.

\section{Animals}

Female BALB/c mice (6-8 weeks old) were supplied by the animal breeding facility at Centro de Pesquisa Gonçalo Moniz (Fundação Oswaldo Cruz, Bahia, Brazil) and maintained in sterilized cages under a controlled environment, receiving a rodent balanced diet and water ad libitum. All experiments were carried out in accordance with the recommendations of Ethical Issues Guidelines, and were approved by the local Animal Ethics Committee. 


\section{Parasite and cell cultures}

Trypanosoma cruzi epimastigotes (Y strain) were maintained at $26^{\circ} \mathrm{C}$ in LIT medium (Liver Infusion Tryptose) supplemented with $10 \%$ fetal bovine serum (FBS; Cultilab, Campinas, Brazil), 1\% haemin (Sigma Chemical Co., St. Louis, MO, USA), 1\% R9 medium (Sigma), and $50 \mu \mathrm{g} \mathrm{mL}^{-1}$ of gentamycin (Novafarma, Anápolis, Brazil). Bloodstream trypomastigote forms of T. cruzi (Y strain) were obtained from the supernatant of infected LLC-MK2 cells and maintained in RPMI-1640 medium (Sigma Chemical Co., St. Louis, MO, USA) supplemented with $10 \% \mathrm{FBS}$ and $50 \mu \mathrm{g} \mathrm{mL}{ }^{-1}$ of gentamycin at $37^{\circ} \mathrm{C}$ with $5 \% \mathrm{CO}_{2}$.

\section{Cytotoxicity to host cells}

Peritoneal exudate macrophages obtained from $\mathrm{BALB} / \mathrm{c}$ mice were placed on 96-well plates at a cell density of $5 \times 10^{5}$ cells $\mathrm{mL}^{-1}$ in $200 \mu \mathrm{L}$ of RPMI1640 medium (no phenol red) and supplemented with $10 \% \mathrm{FBS}$ and $50 \mu \mathrm{g} \mathrm{mL}^{-1}$ of gentamycin and incubated for $24 \mathrm{~h}$ at $37^{\circ} \mathrm{C}$ and $5 \% \mathrm{CO}_{2}$. Compounds were added in a series of eight concentrations $(0 \cdot 13-200 \mu \mathrm{M})$, in triplicate, and incubated for $72 \mathrm{~h}$. $20 \mu \mathrm{L} /$ well of alamar blue (Invitrogen, Carlsbad, USA) was added to all wells during $10 \mathrm{~h}$. Colorimetric readings were performed at 570 and $600 \mathrm{~nm}$. $\mathrm{LC}_{50}$ values were calculated using data-points gathered from three independent experiments. Gentian violet was used as a positive control, at concentrations ranging from 0.04 to $10 \mu \mathrm{M}$.

\section{Antiproliferative activity against epimastigotes}

Epimastigotes were counted in a haemocytometer and dispensed into 96 -well plates at a cell density of $5 \times 10^{6}$ cells $\mathrm{mL}^{-1}$ in $200 \mu \mathrm{L}$ of LIT medium. Compounds were tested at eight concentrations, in triplicate. The plate was incubated for 5 days at $26^{\circ} \mathrm{C}$, aliquots of each well were collected and the number of viable parasites was counted in a Neubauer chamber, which was compared with the untreated parasite culture. This experiment was performed three times. Benznidazole was used as a positive control.

\section{Cytotoxicity for trypomastigotes}

Trypomastigotes collected from the LLC-MK2 cell supernatant were dispensed into 96 -well plates at a cell density of $2 \times 10^{6}$ cells $\mathrm{mL}^{-1}$ in $200 \mu \mathrm{L}$ of RPMI medium. Compounds were tested at eight concentrations, in triplicate. The plate was incubated for $24 \mathrm{~h}$ at $37^{\circ} \mathrm{C}$ and $5 \% \mathrm{CO}_{2}$. Aliquots from each well were collected and the number of viable parasites, based on parasite viability, was assessed in a Neubauer chamber and compared with untreated parasite culture. This experiment was performed three times.

\section{Trypanosoma cruzi infection assay}

Peritoneal exudate macrophages were seeded at a cell density of $10^{6}$ cells $\mathrm{mL}^{-1}$ in a 24 -well plate with round coverslips on the bottom. Cells were cultivated in $1 \mathrm{~mL}$ of RPMI-1640 medium, supplemented with $10 \% \mathrm{FBS}$ and incubated for $24 \mathrm{~h}$. Cells were then infected with trypomastigotes at a ratio of 10 parasites per macrophage for $2 \mathrm{~h}$. Free trypomastigotes were removed by successive washes with saline solution. Cultures were incubated in complete medium, in the presence or absence of physalins B, D, F and G $(1 \mu \mathrm{M})$ or benznidazole $(10 \mu \mathrm{M})$ for $6 \mathrm{~h}$. After this, the supernatant was removed and fresh medium was added and incubated for 4 days. Cells were fixed in absolute alcohol, stained with haematoxylin and eosin and analysed in an optical microscope (Olympus, Tokyo, Japan). The percentage of infected macrophages and the mean number of amastigotes per 100 macrophages was determined by manual counting.

\section{Trypanosoma cruzi invasion assay}

Peritoneal exudate macrophages were cultured at a cell density of $1 \times 10^{5}$ cells $\mathrm{mL}^{-1}$ in a 24 -well plate with rounded coverslips on the bottom in $1 \mathrm{~mL}$ of RPMI-1640 supplemented with 10\% FBS and incubated for $24 \mathrm{~h}$. Cells were then infected with trypomastigotes at a ratio of 100 parasites per macrophage for $2 \mathrm{~h}$, followed by addition of physalin $\mathrm{B}$ or $\mathrm{F}$ (at $10 \mu \mathrm{M})$. Amphotericin B $(10 \mu \mathrm{M})$ was used as a reference inhibitor. The plate was incubated for $2 \mathrm{~h}$ at $37^{\circ} \mathrm{C}$ and $5 \% \mathrm{CO}_{2}$, followed by successive washes with saline solution to remove extracellular trypomastigotes. Plate was maintained in RPMI1640 medium supplemented with $10 \% \mathrm{FBS}$ at $37^{\circ} \mathrm{C}$ for $2 \mathrm{~h}$. Cells were fixed in absolute alcohol, stained with haematoxylin and eosin. The percentage of infected macrophages was determined by manual counting.

\section{Propidium iodide and annexin $V$ staining}

Trypomastigotes $\left(1 \times 10^{7}\right)$ in RPMI-1640 medium supplemented with $10 \%$ FBS were treated with physalin B $(5 \cdot 0 \mu \mathrm{M})$ and incubated for $24 \mathrm{~h}$ at $37^{\circ} \mathrm{C}$. Parasites were labelled with propidium iodide (PI) and annexin $\mathrm{V}$ using the annexin V-FITC apoptosis detection kit (Sigma Chemical Co, St. Louis, MO, USA) according to the manufacturer's instructions. Acquisition was performed using a BD FACS Calibur flow cytometer (San Jose, CA, USA), and data were analysed in BD CellQuest software (San Jose, CA, USA). 


\section{Electron microscopy analysis}

$\mathrm{Y}$ strain $T$. cruzi trypomastigotes $\left(3 \times 10^{7}\right)$ were treated with physalin B $(0.68$ or $1.0 \mu \mathrm{M})$ and incubated for $24 \mathrm{~h}$ at $37^{\circ} \mathrm{C}$. After incubation, parasites were fixed for $1 \mathrm{~h}$ at room temperature with $2 \%$ formaldehyde and $2.5 \%$ glutaraldehyde (Electron Microscopy Sciences, Hatfield, PA, USA) in sodium cacodylate buffer $(0.1 \mathrm{M}, \mathrm{pH} 7 \cdot 2)$ for $1 \mathrm{~h}$ at room temperature. After fixation, parasites were washed 4 times with sodium cacodylate buffer $(0 \cdot 1 \mathrm{M}, \mathrm{pH}$ $7 \cdot 2$ ), and post-fixed with a $1 \%$ solution of osmium tetroxide (Sigma Chemical Co., St. Louis, MO, USA). Cells were subsequently dehydrated in increasing concentrations of acetone $(30,50,70,90$ and $100 \%$ ) for $10 \mathrm{~min}$ at each step and embedded in Polybed resin (PolyScience family, Warrington, PA, USA). Ultrathin sections were prepared on an ultramicrotome Leica UC7 and sections were collected on 300 mesh copper grids, contrasted with uranyl acetate and lead citrate. Images were collected in a JEOL TEM-1230 transmission electron microscope.

\section{Parasitic vacuole staining}

Trypomastigotes $\left(3 \times 10^{7}\right)$ were treated with physalin B $(1.0 \mu \mathrm{M})$ and incubated for $24 \mathrm{~h}$ with $5 \%$ $\mathrm{CO}_{2}$. After treatment, cells were incubated with $100 \mu \mathrm{M}$ of monodansylcadaverine (MDC, Sigma Chemical Co., St. Louis, MO, USA) for $20 \mathrm{~min}$ in the absence of light. After MDC staining, parasites were washed with PBS twice. The parasites were analysed in a FV1000 confocal microscope (Olympus). As a positive control, parasites were treated with $0 \cdot 1 \mu \mathrm{g} \mathrm{mL}^{-1}$ of rapamycin (Sigma Chemical Co., St. Louis, MO, USA).

\section{Cruzain inhibition}

The recombinant cruzain was expressed and purified according to a previously published protocol (Eakin et al. 1993). Protein was activated in acetate buffer $(0 \cdot 1 \mathrm{M}$; pH $5 \cdot 5)$ containing $5.5 \mathrm{~mm}$ of DTT (Invitrogen, Carlsbad, USA) and protein concentration was adjusted to a final concentration of $0 \cdot 1 \mu \mathrm{M}$. Protein was aliquoted into a 96 -well plate, and compounds (previously dissolved in DMSO) in phosphate buffer (in the presence of $0.01 \%$ Triton 100) were added to the respective wells. The plate was incubated for $10 \mathrm{~min}$ at $35^{\circ} \mathrm{C}$. After this time, a solution containing protease substrate Z-FR-AMC (Sigma Chemical Co., St. Louis, MO, USA) was added, and following incubation periods 1, 5 or $10 \mathrm{~min}$, the plate was read using the EnVision multilabel reader (PerkinElmer, Shelton, CT, USA). The percentage of cruzain inhibition was calculated using the following equation: $100-(\mathrm{A} 1 / \mathrm{A} \times 100)$, where $\mathrm{A} 1$ represents the cruzain $\mathrm{RFU}$ in the presence of the test inhibitor, A refers to the control RFU (cruzain and substrate only). Compound concentration was measured in triplicate. $(2 S, 3 S)$-transepoxysuccinyl-L-leucylamido-3-methylbutane (E-64c) was purchased from Sigma Chemical Co. (catalogue number E0514) and used as a standard cruzain inhibitor.

\section{Statistical analyses}

We used a non-linear regression for calculating $\mathrm{LC}_{50}$ and $\mathrm{IC}_{50}$ values. The selectivity index (SI) was defined as the ratio of $\mathrm{LC}_{50}$ by $\mathrm{IC}_{50}$ (trypomastigotes). The one-way ANOVA and Bonferroni multiple comparisons were used to determine the statistical significance of the group comparisons in the in vitro infection studies and cell invasion study. Results were considered statistically significant when $P<0 \cdot 05$. All analyses were performed using Graph Pad Prism version 5.01 (Graph Pad Software, San Diego, CA, USA).

\section{RESULTS}

\section{Trypanocidal and cytotoxicity activity}

First, we evaluated the trypanocidal activity of physalins B, D, F and $\mathrm{G}$ against axenic epimastigotes and bloodstream trypomastigotes from the $\mathrm{Y}$ strain of $T$. cruzi. Cytotoxicity was determined in mouse macrophages. Benznidazole and gentian violet were used as trypanocidal and cytotoxic reference drugs, respectively. Activity was described in term of $\mathrm{IC}_{50}$ or $\mathrm{LC}_{50}$ values (Table 1 ). Of these, only physalins $\mathrm{B}$ and $\mathrm{F}$ were able to inhibit epimastigote proliferation, with $\mathrm{IC}_{50}$ values of $5 \cdot 3 \pm 1 \cdot 9$ and $5 \cdot 8 \pm 1 \cdot 5 \mu \mathrm{M}$, respectively, while benznidazole exhibited an $\mathrm{IC}_{50}$ $10 \cdot 8 \pm 0 \cdot 9 \mu \mathrm{M}$. All physalins exhibited activity against trypomastigotes. Once again, physalins $\mathrm{B}$ and $\mathrm{F}$ were the most active, presenting $\mathrm{IC}_{50}$ values of $0 \cdot 68 \pm 0 \cdot 01$ and $0.84 \pm 0.04 \mu \mathrm{M}$ respectively, while an $\mathrm{IC}_{50}$ of $11 \cdot 4 \pm 1 \cdot 8 \mu \mathrm{M}$ was calculated for benznidazole-treated trypomastigotes.

Next, physalin cytotoxicity to host cells (mouse macrophages) was analysed. Compared with gentian violet $\left(\mathrm{LC}_{50} 0 \cdot 48 \pm 0 \cdot 05 \mu \mathrm{M}\right)$, the cytotoxic reference drug in this assay, physalins demonstrated a lower cytotoxic value. Physalins $D$ and $G$ exhibited cytotoxicity similar to each other and they were less cytotoxic than physalins B and F. Regarding the cellular SI, physalins B and F exhibited a selectivity of 13 and 12 respectively, while physalins D and $G$ were two times less selective.

\section{Investigating the mechanism of action}

After confirming that physalins were able to kill parasites, our next step was to understand how they affect parasite cells. In the first set of experiments 
Table 1. Cruzain activity, cytotoxicity in macrophages and anti-Trypanosoma cruzi activity of purified physalins

\begin{tabular}{|c|c|c|c|c|c|}
\hline \multirow[b]{2}{*}{ Compounds } & \multirow{2}{*}{$\begin{array}{l}\% \text { cruzain } \\
\text { inhibition } \\
\text { at } 25 \mu \mathrm{M}^{\mathrm{a}}\end{array}$} & \multirow{2}{*}{$\begin{array}{l}\text { Host cells } \\
\mathrm{LC}_{50} \pm \mathrm{s} . \mathrm{D} . \\
(\mu \mathrm{M})^{\mathrm{b}}\end{array}$} & \multicolumn{2}{|c|}{$\mathrm{Y}$ strain $T . c r u z i, \mathrm{IC}_{50} \pm$ s.D. $(\mu \mathrm{M})$} & \multirow[b]{2}{*}{$\mathrm{SI}^{\mathrm{e}}$} \\
\hline & & & Epimastigotes $^{c}$ & Trypomastigotes ${ }^{\mathrm{d}}$ & \\
\hline Physalin B & 0 & $9 \cdot 4 \pm 0 \cdot 15$ & $5 \cdot 3 \pm 1 \cdot 9$ & $0 \cdot 68 \pm 0 \cdot 01$ & 13 \\
\hline Physalin D & 5 & $>200$ & NA & $37 \cdot 5 \pm 0 \cdot 70$ & 5 \\
\hline Physalin F & 1 & $10 \cdot 1 \pm 0 \cdot 7$ & $5 \cdot 8 \pm 1 \cdot 5$ & $0 \cdot 84 \pm 0 \cdot 04$ & 12 \\
\hline Physalin G & 0 & $98 \cdot 4 \pm 2 \cdot 4$ & NA & $12 \cdot 7 \pm 1 \cdot 7$ & 7 \\
\hline Benznidazole & - & $>200$ & $10 \cdot 8 \pm 0 \cdot 9$ & $11 \cdot 4 \pm 1 \cdot 8$ & 18 \\
\hline Gentian violet & - & $0 \cdot 48 \pm 0 \cdot 05$ & - & - & - \\
\hline E-64c & 100 & - & - & - & - \\
\hline
\end{tabular}

${ }^{\text {a }}$ Determined after 5 min of incubation with enzyme.

$\mathrm{b}$ Determined in BALB/c macrophages after $72 \mathrm{~h}$ of incubation with the compounds.

c Determined after 5 days of incubation.

d Determined after $24 \mathrm{~h}$ of incubation.

e $\mathrm{SI}=$ selectivity index. NA = no activity.

S.D. $=$ standard deviation. $\mathrm{IC}_{50}$ and $\mathrm{LC}_{50}$ values are means \pm s.D. of two or three independent experiments performed in triplicate.

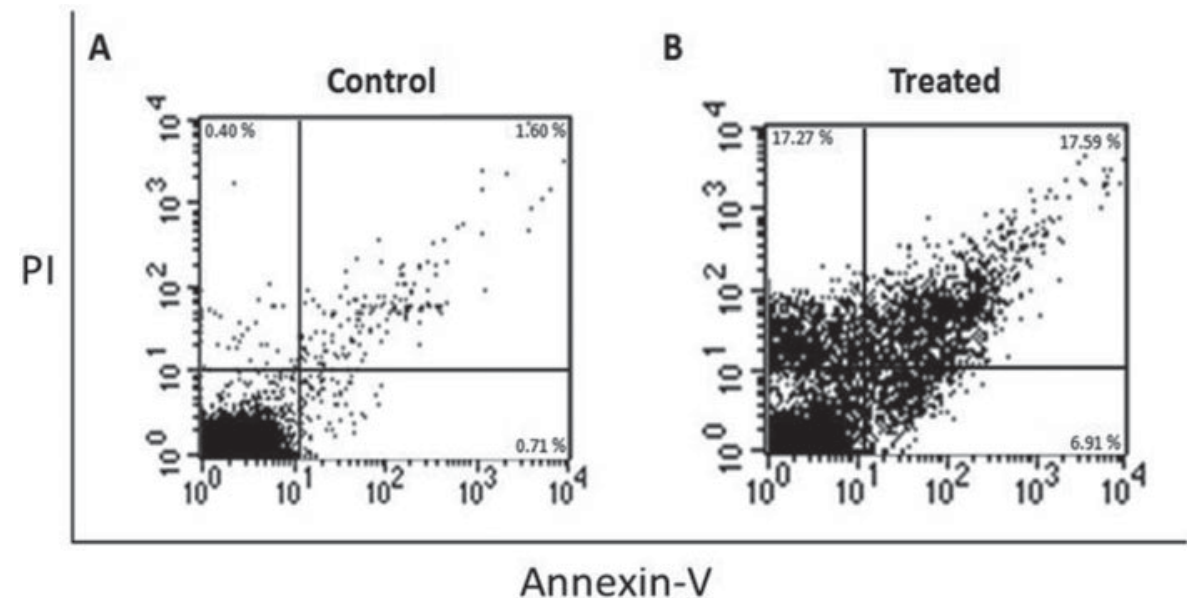

Fig. 2. Physalin B causes parasite cell death by a necrotic process. Flow cytometry examination of annexin V and propidium iodide staining in Trypanosoma cruzi trypomastigotes treated with $5 \mu \mathrm{M}$ of physalin B for $24 \mathrm{~h}$. (A), untreated parasites; (B), physalin B-treated parasites.

investigating the mechanism of action, we treated $\mathrm{Y}$ strain trypomastigotes with $5 \mu \mathrm{M}$ of physalin $\mathrm{B}$, which were incubated for $24 \mathrm{~h}$. Cells were then stained with annexin $\mathrm{V}$ and PI and examined by flow cytometry. As shown in Fig. 2, most of the parasite cells treated with physalin B were positively stained for PI when compared with untreated cells. Therefore, physalin-based treatment causes parasite cell death through necrosis induction.

In the second set of experiments, we used electron microscopy to examine the ultrastructural morphology of trypomastigotes treated with physalin B. As we can see in Fig. 3, parasites exhibited kinetoplast enlargement, alterations in the Golgi complex, as well as endoplasmic reticulum morphology. Interestingly, we also observed the presence of myelin-like figures within the cytoplasm. To confirm that these myelin-like figures are parasitic vacuoles, possibly related to autophagy, untreated or treated trypomastigotes were incubated with monodansylcadaverine (MDC) for $20 \mathrm{~min}$ and observed by fluorescence microscopy. In a control experiment, untreated cells presented no detectable MDC staining, while rapamycin-treated cells contained stained cytosolic vacuoles. Following this, we tested physalin $\mathrm{B}(1 \cdot 0 \mu \mathrm{M})$ which clearly presented stained vacuoles (Fig. 4).

Finally, we tested the ability of physalins to inhibit the activity of recombinant cruzain, the major T. cruzi cysteine protease. As Table 1 demonstrates, none of the physalins tested at a concentration of $25 \mu \mathrm{m}$ exhibited inhibitory properties against cruzain.

\section{Physalins inhibit T. cruzi infection in host cells}

We tested physalins to inhibit the parasite development in host cells. In this assay, mouse macrophages 

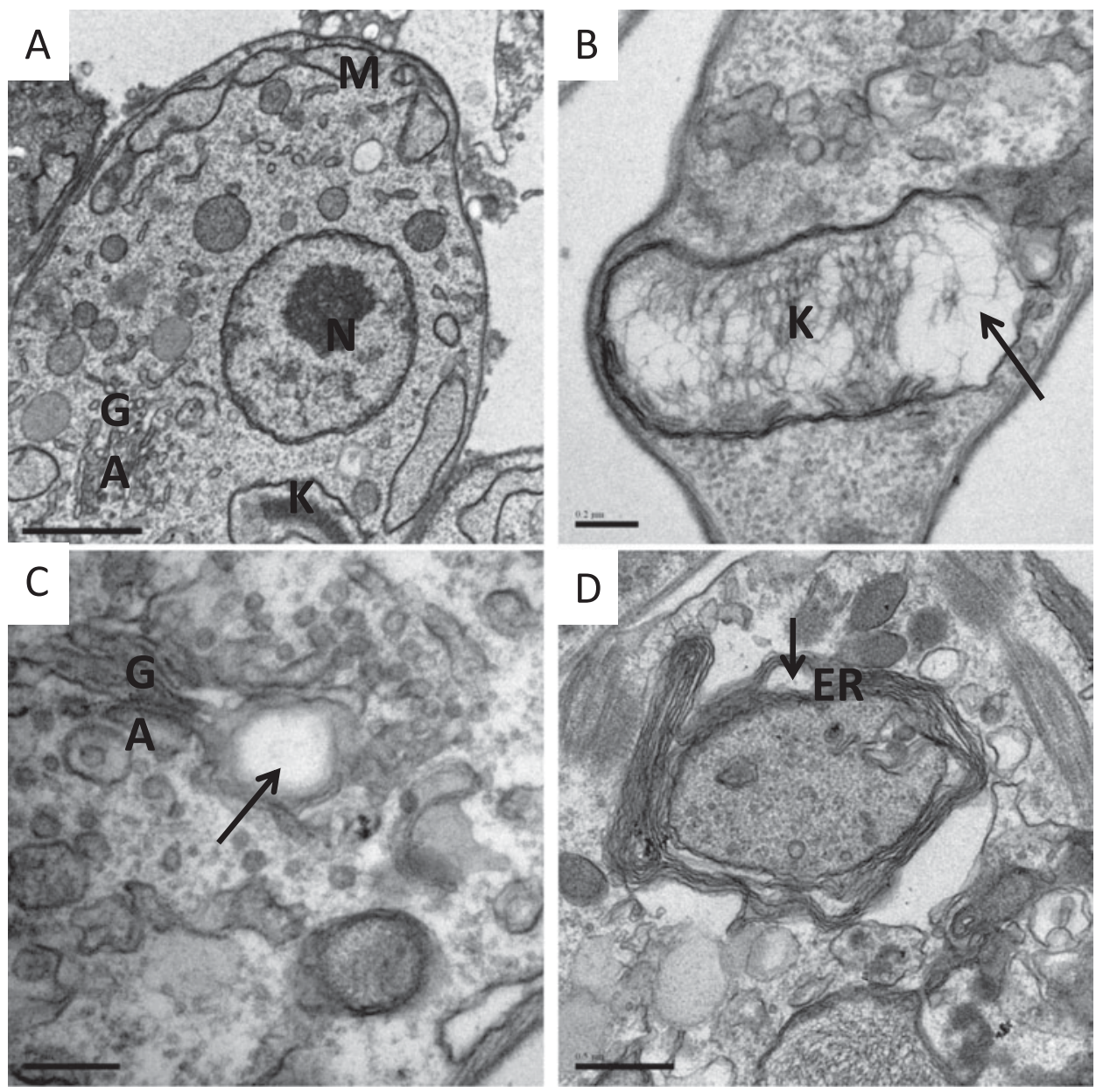

Fig. 3. Physalin B induces significant ultrastructural changes in trypomastigotes. (A) shows an image of untreated parasites presenting a typical morphology of the nucleus $(\mathrm{N})$, kinetoplast $(\mathrm{K})$, mitochondria (M) and Golgi apparatus (GA). Treatment for $24 \mathrm{~h}$ with physalin B at 0.68 (B and C) or $1.0 \mu \mathrm{M}$ (D) causes kinetoplast enlargement (B), Golgi apparatus disorganization (C) and endoplasmic reticulum disorganization (D). Black arrows indicate changes in organelles. Scale bars: $A=1 \mu \mathrm{m} ; \mathrm{B}$ and $\mathrm{C}=0 \cdot 2 \mu \mathrm{m} ; \mathrm{D}=0.5 \mu \mathrm{m}$.

were infected with Y strain trypomastigotes. After infection, the respective physalin $(1 \cdot 0 \mu \mathrm{M})$ was added to the cell culture. Benznidazole was included in this assay as a positive control. Cells were stained with haematoxylin and eosin and analysed by optical microscopy 4 days post-infection. As shown in Fig. 5, physalins $\mathrm{B}$ and $\mathrm{F}$ significantly reduced the percentage of infected macrophages and the relative numbers of intracellular parasites when compared with control. Interestingly, activity of physalins $\mathrm{B}$ and $\mathrm{F}$ was quite similar to that observed in benznidazole. In contrast, physalins D and G did not show significant activity in this assay. When physalins $\mathrm{B}$ and $\mathrm{F}$ were tested in concentrations above $1 \cdot 0 \mu \mathrm{M}$, they did not inhibit infection in macrophages, probably due to their immunosuppressive properties (data not shown).

In another experiment, we measure physalins' ability to impair parasite invasion into host cells. In this assay, mouse macrophages were exposed to trypomastigotes and at the same time treated with physalins $(10 \mu \mathrm{M})$. After incubating for $2 \mathrm{~h}$, cell cultures were stained and analysed by optical microscopy. Amphotericin B was used as a positive control. As shown in Fig. 6, physalins B and F significantly inhibited the parasite invasion process in macrophages when compared with untreated cultures. Curiously, while physalins exhibited activity in this assay, equal concentrations of benznidazole did not.

Based on the results described above, a final set of experiments was performed to evaluate the activity in infected macrophages of physalin $\mathrm{B}$ or $\mathrm{F}$ in combination with benznidazole. As shown in Fig. 7 , the combination of physalin and benznidazole reduced the number of infected macrophages as well as the number of amastigotes per macrophage to a greater degree than the respective compound used alone.

\section{DISCUSSION}

Pharmacological treatment of Chagas disease has been limited to benznidazole, which has poor efficacy 
Differential interference contrast (DIC)
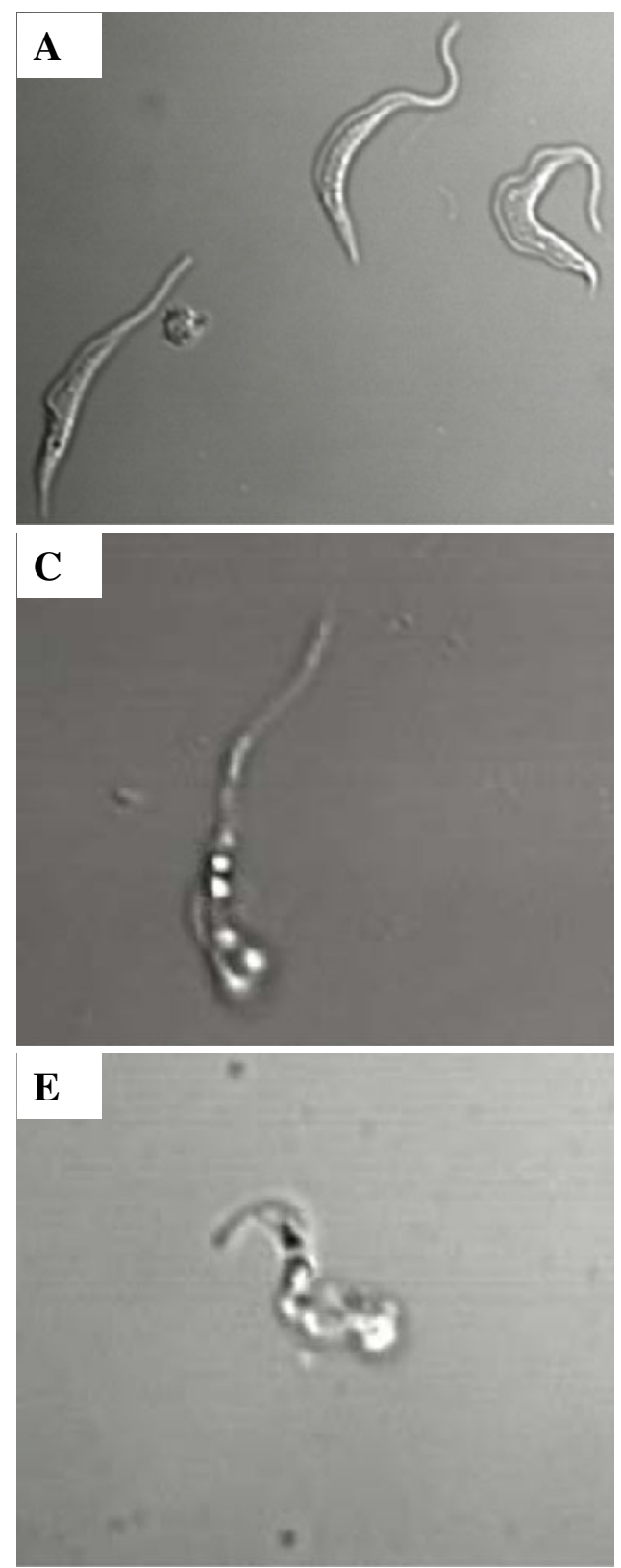

\section{Fluorescence microscopy}

\section{B}

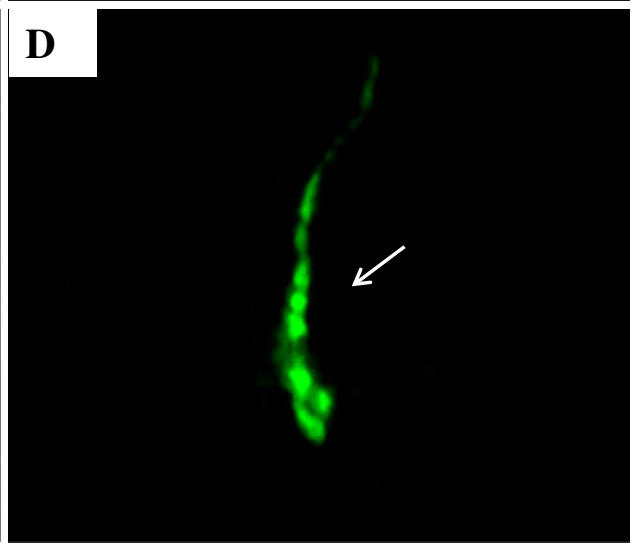

\section{$\mathbf{F}$}

Fig. 4. Physalin B induces the formation of cytosolic vacuoles in Trypanosoma cruzi. Trypomastigotes treated with $1.0 \mu \mathrm{M}$ of physalin for $24 \mathrm{~h}$ and incubated with MDC for $20 \mathrm{~min}$. Left panels are DIC and right panels are fluorescence microscopy. (A) and (B) show untreated trypomastigotes; (C) and (D) show parasite treated with $0 \cdot 1 \mu \mathrm{g} \mathrm{mL} \mathrm{L}^{-1}$ of rapamycin (positive control); (E, F) show treated trypomastigotes with physalin B. Arrows indicate the vacuole structures. Images were captured on confocal microscope with a $60 \times$ oil-immersion objective at $3 \times$ zoom.

and causes drug intolerance, as well as adverse effects in many patients. Emergence of parasite resistance to benznidazole is another subject of concern. A large number of small molecules have been screened as anti-T. cruzi agents, however the number is still low when compared with drug discovery efforts for other infectious diseases, such as malaria and AIDS (Goebel et al. 2008). Screening of isolated natural compounds is a reliable strategy to identify new antiT. cruzi agents.
The Physalis genus is a rich source of unique natural compounds. Of these, the seco-steroids physalins are the most investigated in terms of pharmacological property. We previously reported that physalins isolated from $P$. angulata L. are potent immunomodulatory, antileishmanial and antiplasmodial agents. In 2008, Vieira and co-workers reported that physalin $\mathrm{F}$ and withaphysalins inhibit proliferation of T. cruzi epimastigotes in an axenic medium (Vieira et al. 2008). Additionally, Castro and 
A

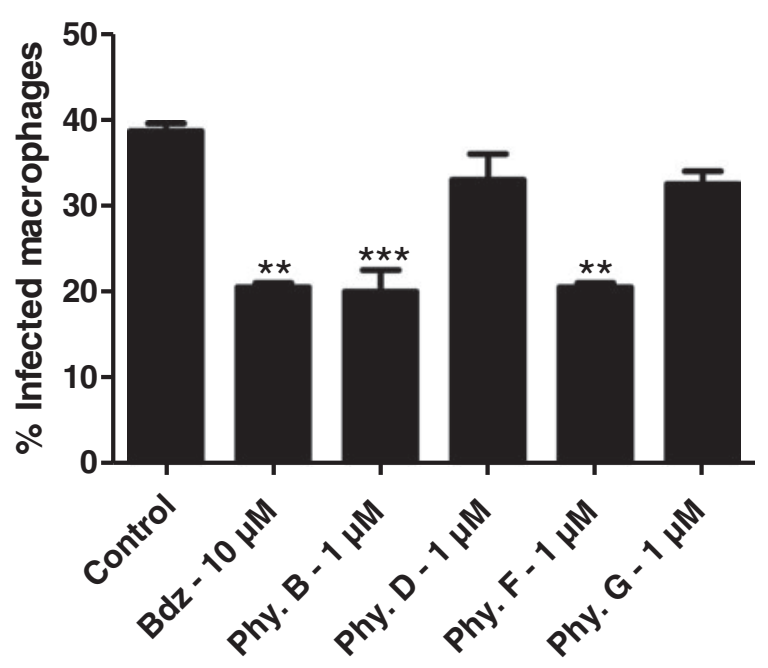

B

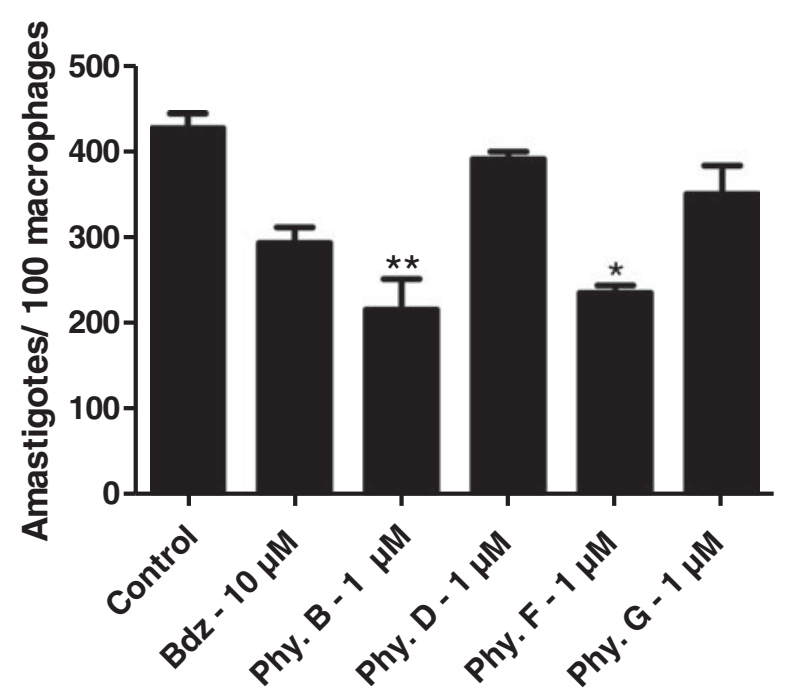

Fig. 5. Physalins $\mathrm{B}$ and $\mathrm{F}$ inhibit intracellular amastigotes in host cells. Mouse peritoneal macrophages were infected with $\mathrm{Y}$ strain trypomastigotes for $2 \mathrm{~h}$ and treated with the respective physalin $(1 \cdot 0 \mu \mathrm{M})$. Infected cells were stained with haematoxylin and eosin and analysed by optical microscopy. (A) shows the percentage of infected macrophages; (B) displays the relative number of amastigotes per 100 macrophages. $\mathrm{Bdz}=$ Benznidazole; Phy. $=$ physalin. Values represent the mean \pm s.E.M. in triplicate. ${ }^{*} P<0 \cdot 05$; ** $P<0 \cdot 01$; *** $P<0 \cdot 001$ compared with the control group.

co-workers corroborated these findings, showing that physalin B inhibits T.cruzi development in the gut of triatomines (Castro et al. 2009, 2012). However, the anti-T. cruzi activity of physalins against the infective forms in humans (bloodstream trypomastigotes and amastigotes) have not been described.

In the present study, we determined the antiT. cruzi activity of physalins B, D, F and G purified from $P$. angulata. Only physalin $\mathrm{F}$ was previously tested against epimastigotes, therefore we performed an extensive examination of all physalins. As expected,

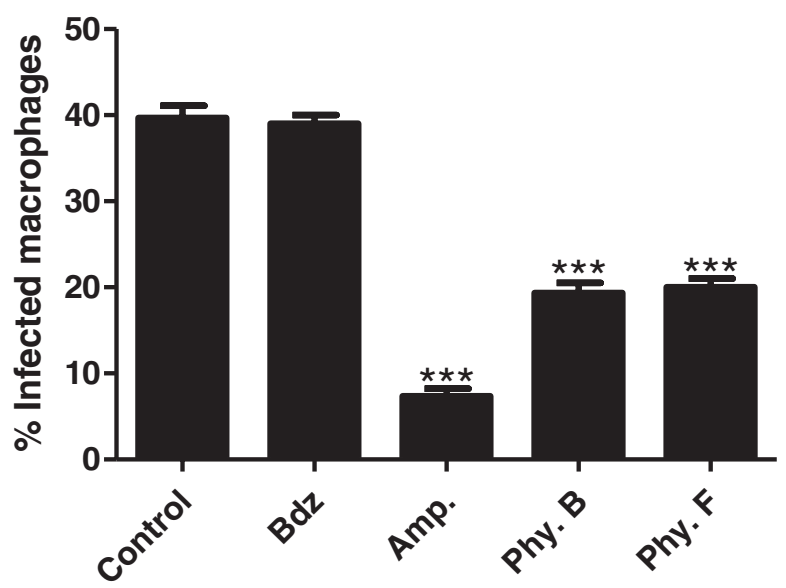

Fig. 6. Physalins $\mathrm{B}$ and $\mathrm{F}$ reduce the parasite invasion process in host cells. Mouse macrophages were infected with Y strain trypomastigotes and at the same time treated with physalins. The percentage of T. cruziinfected macrophages is shown. $\mathrm{Bdz}=$ benznidazole, Amp $=$ amphotericin B. Values represent the mean \pm s.E.M. in triplicate. ${ }^{* * *} P<0.001$ compared with the control group.

we observed that physalins, specifically $\mathrm{B}$ and $\mathrm{F}$, are trypanocidal agents. They inhibited epimastigote proliferation, and were toxic against bloodstream trypomastigotes at non-toxic concentrations for mouse macrophages. In addition, they showed a greater potency when compared with benznidazole, the reference anti-T. cruzi drug. Regarding the cellular $\mathrm{SI}$, physalins $\mathrm{B}$ and $\mathrm{F}$ exhibited some selectivity, albeit low for a desirable anti-T. cruzi drug candidate.

The chemical difference amongst the four physalins is found in the substituents attached to C5 and $\mathrm{C} 6$ in the steroid backbone. Physalins D and G are similar because of the hydroxyl groups present and they did not exhibit trypanocidal activity. In contrast, physalin $\mathrm{B}$ and $\mathrm{F}$ lack hydroxyl groups in $\mathrm{C} 5$ and $\mathrm{C} 6$, and demonstrated higher activity, exhibiting a pronounced trypanocidal property. In practice, physalin $\mathrm{B}$ and $\mathrm{F}$ have equipotent trypanocidal activity.

By using trypomastigotes, we observed that physalins cause parasite cell death through necrotic mechanisms. Also, we saw that physalins alter the morphology of the Golgi complex, kinetoplast and endoplasmic reticulum. In the literature, altered Golgi complex morphology is an indication that T. cruzi protease activity was affected (Engel et al. 1998). Cruzain is the major cysteine protease present in T. cruzi and has been identified as a drug target (Sajid et al. 2011). Therefore, we determined the ability of physalins to inhibit the activity of recombinant cruzain; however, physalins did not inhibit it.

Using electron microscopy, formation of myelinlike figures in the parasite treated with physalins was evident. Fluorescence microscopy revealed that parasites treated with physalins were labelled with 
A

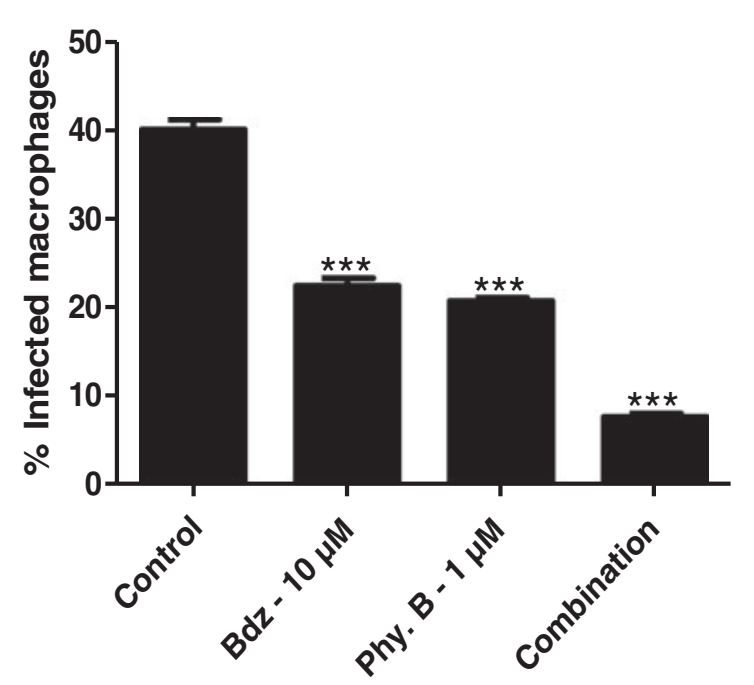

C

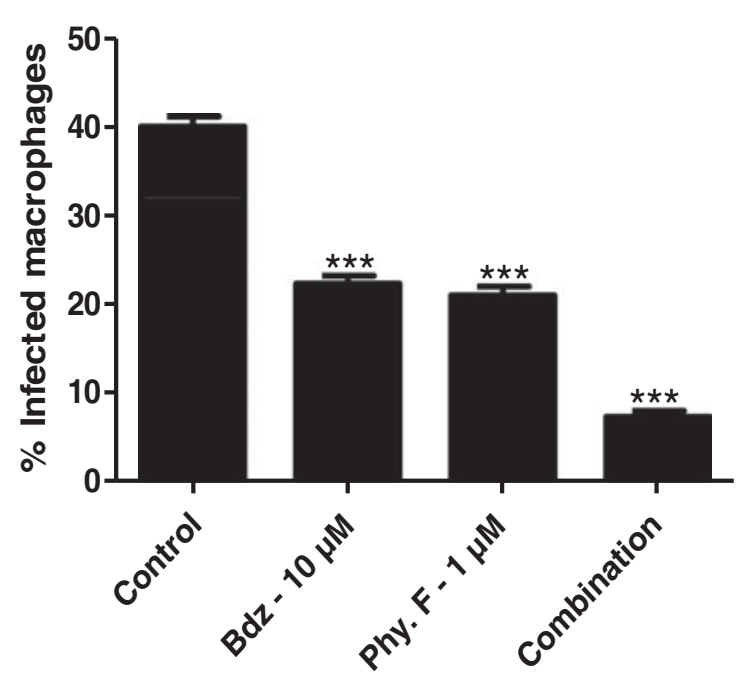

B
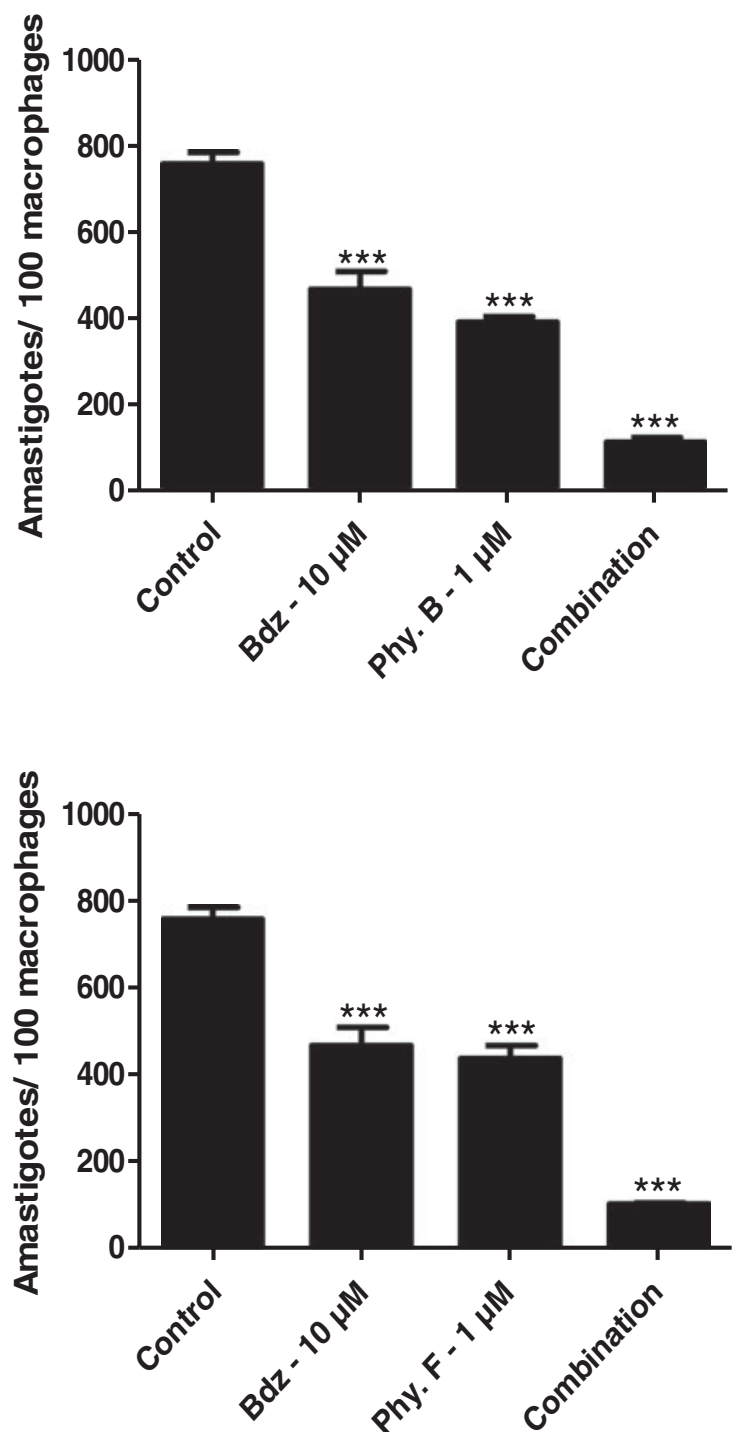

Fig. 7. A combination of physalin and benznidazole is more potent to inhibit amastigotes than compounds when used alone. Mouse peritoneal macrophages were infected with $\mathrm{Y}$ strain trypomastigotes for $2 \mathrm{~h}$. Physalin B or F was added alone or in combination with benznidazole. (A) and (B) show the combination of physalin B and benznidazole, while (C) and (D) display the combination of physalin F and benznidazole. Bdz = Benznidazole. Values represent the mean \pm s.E.M. in triplicate. ${ }^{*} * * P<0 \cdot 001$ compared with the control group.

MDC, a cytosolic vacuole stain (Vanier-Santos and Castro, 2009; Duszenko et al. 2011). Therefore, it is possible that the cytosolic vacuoles observed in physalin-treated $T$. cruzi are due to autophagy. In fact, our results are similar to a very recent finding that physalins exert cellular effects by inducing autophagy (He et al. 2013a, b).

Most importantly, we analysed physalin effects in the in vitro infection. The same order of potency against trypomastigotes was observed when all physalins were tested in T. cruzi-infected macrophages. Physalins $\mathrm{B}$ and $\mathrm{F}$ at $1 \cdot 0 \mu \mathrm{M}$ were able to reduce intracellular parasite development in macrophages. This was similar to reductions observed in benznidazole-treated infected cells. Physalins B and $\mathrm{F}$ are well known for their modulatory property in immune cells (Soares et al. 2003, 2006). In fact, we observed that physalin $\mathrm{B}$ or $\mathrm{F}$ at concentrations of $5 \cdot 0 \mu \mathrm{M}$ or higher increased the T. cruzi infection in macrophages, probably because they deactivate host macrophages during the infection development.

The parasite invasion process in macrophages takes approximately $2 \mathrm{~h}$, thereby requiring a drug to work quickly (Matsuo et al. 2010). In this assay, benznidazole was not active, while amphotericin B was active to stop the parasite invasion. Interestingly, physalins $\mathrm{B}$ and $\mathrm{F}$ not only reduced parasite burden in infected macrophages, but they also quickly killed trypomastigotes exposed to macrophages, therefore indicating seco-steroids stop the parasite invasion process in host cells.

An anti-Chagas disease treatment will likely contain a combination of inhibitors to improve the efficacy of the treatment and avoid parasite resistance. 
In recent years, many efforts have been done to identify optimal drug combinations for Chagas disease (Cencig et al. 2012; Veiga-Santos et al. 2012). In fact, we observed the combination of physalin and benznidazole has a greater activity to reduce T. cruzi infection in macrophages than compounds used alone. The results indicate that the combination of physalin and benznidazole act in an additive fashion. Altogether, these data argue that the screening for new anti-T. cruzi agents based on secosteroids, specifically those without or with little effects on immune cells, is an attractive line of drug development.

\section{CONCLUSION}

Physalins showed potent activity against T. cruzi epimastigotes and trypomastigotes. Of these, physalins $B$ and $F$ exhibited the highest potency and selectivity, and similar to the observations on benznidazole-treated parasites. These compounds achieve trypanocidal activity through autophagy induction, which ultimately results in necrotic parasite death. Regarding the in vitro infection, we observed physalins inhibit parasite development, as well as the invasion process in host cells. Moreover, physalins seem suitable for drug combination with other anti-T. cruzi agents to control infection.

\section{ACKNOWLEDGEMENTS}

M. B. P. S. and R. R. S hold a CNPq fellowship, while D. R. M. M. and C. S. M. thank for FAPESB scholarships.

\section{F I NANCIAL SUPPORT}

This work received funding by Conselho Nacional de Pesquisas Brasileira (CNPq, grant number 502161/2010-8) and Fundação de Amparo as Pesquisas do Estado da Bahia (FAPESB, grant number 6596).

\section{COMPETING INTERESTS}

The authors have declared that no competing interests exist.

\section{REFERENCES}

Brustolim, D., Vasconcelos, J.F., Freitas, L. A., Teixeira, M. M. Farias, M. T., Ribeiro, Y.M., Tomassini, T. C.B., Oliveira, G. G., Pontes-de-Carvalho, L. C., Ribeiro-dos-Santos, R. and Soares, M. B.P. (2010). Activity of physalin F in a collagen-induced arthritis model. Fournal of Natural Products 73, 1323-13236. doi: 10.1021/ np900691w.

Castro, D. P., Figueiredo, M. B., Genta, F. A., Ribeiro, I. M., Tomassini, T. C. B., Azambuja, P. and Garcia, E. S. (2009). Physalin $\mathrm{B}$ inhibits Rhodnius prolixus hemocyte phagocytosis and microaggregation by the activation of endogenous PAF-acetyl hydrolase activities. Fournal of Insect Physiology 55, 532-537. doi: 10.1016/j.jinsphys.2009.01.013.

Castro, D.P., Moraes, C.S., Gonzalez, M.S., Ribeiro, I. M., Tomassini, T. C., Azambuja, P. and Garcia, E. S. (2012). Physalin B inhibits Trypanosoma cruzi infection in the gut of Rhodnius prolixus by affecting the immune system and microbiota. Fournal of Insect Physiology 58, 1620-1625. doi: 10.1016/j.jinsphys.2012.10.001.
Cencig, S., Coltel, N., Truyens, C. and Carlier, Y. (2012). Evaluation of benznidazole treatment combined with nifurtimox, posaconazole or AmBisome ${ }^{\circledR}$ in mice infected with Trypanosoma cruzi strains. International Fournal of Antimicrobial Agents 40, 527-532. doi: 10.1016/j.ijantimicag. 2012.08.002.

Chiang, H. C., Jaw, S. M. and Chen, P. M. (1992). Inhibitory effects of physalin $\mathrm{B}$ and physalin $\mathrm{F}$ on various human leukemia cells in vitro. Anticancer Research 12, 1155-1162.

Coura, J. R. and De Castro, S. L. (2002). A critical review on Chagas disease chemotherapy. Memorias Instituto Oswaldo Cruz 97, 3-24. doi: 10.1590/S0074-02762002000100001.

Damu, A. G., Kuo, P.C., Su, C.R., Kuo, T.H., Chen, T.H., Bastow, K. F., Lee, K. H. and Wu, T.S. (2007). Isolation, structures, and structure - cytotoxic activity relationships of withanolides and physalins from Physalis angulata. Fournal of Natural Products 70, 1146-1152. doi: 10.1021/np0701374.

Duszenko, M., Ginger, M.L., Brennand, A., Gualdrón-López, M., Colombo, M. I., Coombs, G. H., Coppens, I., Jayabalasingham, B., Langsley, G., de Castro, S. L., Menna-Barreto, R., Mottram, J. C., Navarro, M., Rigden, D. J., Romano, P.S., Stoka, V., Turk, B. and Michels, P. A. (2011). Autophagy in protists. Autophagy 7, 127-158. doi: 10.4161/auto.7.2.13310.

Eakin, A. E., MacGrath, M. E., McKerrow, J. H., Fletterick, R. J. and Craik, C.S. (1993). Production of crystalizable cruzain, the major cysteine protease from Trypanosoma cruzi. Fournal of Biological Chemistry 268, 61156118 .

Engel, J. C., Doyle, P.S., Palmer, J., Hsieh, I., Bainton, D. F. and McKerrow, J. H. (1998). Cysteine protease inhibitors alter Golgi complex ultrastructure and function in Trypanosoma cruzi. Fournal of Cell Science 111, 597-606.

Goebel, T., Ulmer, D., Projahn, H., Kloeckner, J., Heller, E., Glaser, M., Ponte-Sucre, A., Specht, S., Sarite, S. R., Hoerauf, A., Kaiser, A., Hauber, I., Hauber, J. and Holzgrabe, U. (2008). In search of novel agents for therapy of tropical diseases and human immunodeficiency virus. Fournal of Medicinal Chemistry 51, 238-250. doi: 10.1021/ jm070763y.

Guimarães, E.T., Lima, M.S., Santos, L. A., Ribeiro, I. M., Tomassini, T. C. B., Ribeiro dos Santos, R., dos Santos, W. L. and Soares, M. B.P. (2009). Activity of physalins purified form Physalins angulata in vitro and in vivo models of cutaneous leishmaniasis. Fournal of Antimicrobial Chemotherapy 64, 84-87. doi: 10.1093/jac/dkp170.

Gupta, S., Wan, X., Zago, M. P., Sellers, V. C., Silva, T. S., Assiah, D., Dhiman, M., Nuñez, S., Petersen, J. R., Vázquez-Chagoyán, J. C., Estrada-Franco, J. G. and Garg, N. J. (2013). Antigenicity and diagnostic potential of vaccine candidates in human Chagas disease. PLOS Neglected Tropical Diseases 7, e2018. doi: 10.1371/journal.pntd.0002018.

He, H., Zang, L. H., Feng, Y.S., Wang, J., Liu, W. W., Chen, L. X., Kang, N., Tashiro, S., Onodera, S., Qiu, F. and Ikejima, T. (2013a). Physalin A induces apoptotic cell death and protective autophagy in HT1080 human fibrosarcoma cells. Fournal of Natural Products 76, 880-888. doi: 10.1021/np400017k.

He, H., Zang, L. H., Feng, Y.S., Chen, L. X., Kang, N., Tashiro, S. I., Onodera, S., Qiu, F. and Ikejima, T. (2013b). Physalin A induces apoptosis via p53-Noxa-mediated ROS generation, and autophagy plays a protective role against apoptosis through $\mathrm{p} 38-\mathrm{NF}-\mathrm{\kappa B}$ survival pathway in A375-S2 cells. Fournal of Ethnopharmacology 148, 544-555. doi: 10.1016/j. jep.2013.04.051.

Jacobo-Herrera, N. J., Bremner, P., Marquez, N., Gupta, M.P., Gibbons, S., Muñoz, E. and Heinrich, M. (2006). Physalins from Witheringia solanaceas as modulators of the NF-kappaB cascade. Fournal of Natural Products 69, 328-331. doi: 10.1021/np050225t.

Januário, A. H., Filho, E. R., Pietro, R. C., Kashima, S., Sato, D. N. and França, S. C. (2002). Antimycobacterial physalins from Physalis angulata L. (Solanaceae). Phytotherapy Research 16, 445-448. doi: 10.1002/ptr. 939. Jin, Z., Mashuta, M. S., Stolowich, N. J., Vaisberg, A. J., Stivers, N. S., Bates, P. J., Lewis, W. H. and Hammond, G. B. (2012). Physangulidines A, B, and C: three new antiproliferative withanolides from Physalis angulata L. Organic Letters 14, 1230-1233. doi: 10.1021/ol203498a.

Pinto-Dias, J. C. (2006). The treatment of Chagas disease (South American trypanosomiasis). Annals of Internal Medicine 144, 722-774.

Magalhães, H. I., Veras, M. L., Torres, M. R., Alves, A.P., Pessoa, O. D., Silveira, E. R., Costa-Lotufo, L. V., de Moraes, M. O. and Pessoa, C. (2006). In vitro and in vivo antitumor activity of physalins B and D from Physalis angulata. Fournal of Pharmacy and Pharmacology 58, 235-241. doi: 10.1211/jpp.58.2.0011.

Maya, J. D., Cassels, B. K., Iturriaga-Vásquez, P., Ferreira, J., Faúndez, M., Galanti, N., Ferreira, A. and Morello, A. (2007). Mode of action of natural and synthetic drugs against Trypanosoma cruzi and their 
interaction with the mammalian host. Comparative Biochemistry and Physiology Part A: Molecular and Integrative Physiology 146, 601-620. doi: 10.1016/j.cbpa.2006.03.004.

Matsuo, A.L., Silva, L.S., Torrecilhas, A. C., Pascoalino, B.S., Ramos, T. C., Rodrigues, E. G., Schenkman, S., Caires, A.C. and Travassos, L.R. (2010). In vitro and in vivo trypanocidal effects of the cyclopalladated compound $7 \mathrm{a}$, a drug candidate for treatment of Chagas' disease. Antimicrobial Agents and Chemotherapy 54, 3318-3325. doi: 10.1128/AAC.00323-10.

Moncayo, A. and Silveira, A. C. (2009). Current epidemiological trends for Chagas disease in Latin America and future challenges in epidemiology, surveillance and health policy. Memorias Instituto Oswaldo Cruz 104, 17-30. doi: 10.1590/S0074-02762009000900005.

Moreno, M., D'avoça, D. A., Silva, M. N., Galvão, L. M., Macedo, A. M., Chiari, E., Gontijo, E. D. and Zingales, B. (2010). Trypanosoma cruzi benznidazole susceptibility in vitro does not predict the therapeutic outcome of human Chagas disease. Memorias Instituto Oswaldo Cruz 105, 918-924. doi: 10.1590/S0074-02762010000700014.

Moton, A., Krishna, G. and Wang, Z. (2009). Tolerability and safety profile of posaconazole: evaluation of 18 controlled studies in healthy volunteers. Fournal of Clinical Pharmacy and Therapeutics 34, 301-311. doi: 10.1111/j.1365-2710.2009.01055.x.

Reyes-Reyes, E. M., Jin, Z., Vaisberg, A. J., Hammond, G. B. and Bates, P. J. (2013). Physangulidine A, a withanolide from Physalis angulata, perturbs the cell cycle and induces cell death by apoptosis in prostate cancer cells. Fournal of Natural Products 76, 2-7. doi: 10.1021/np300457g.

Sá, M.S., Menezes, M. N., Krettli, A. U., Ribeiro, I. M., Tomassini, T. C. B., Ribeiro dos Santos, R., de Azevedo, W. F., Jr. and Soares, M. B. P. (2011). Antimalarial activity of physalins B, D, F and G. Fournal of Natural Products 74, 2269-2272. doi: 10.1021/np200260f. Sajid, M., Robertson, S.A., Brinen, L.S. and McKerrow, J.H. (2011). Cruzain: the path from target validation to the clinic. Advances in Experimental Medicine and Biology 712, 100-115. doi: 10.1007/978-1-44198414-2_7.
Soares, M. B. P., Bellintani, M. C., Ribeiro, I. M., Tomassini, T. C. B. and Ribeiro dos Santos, R. (2003). Inhibition of macrophage activation and lipopolysaccharide-induced death by seco-steroids purified from Physalis angulata L. European Fournal of Pharmacology 459, 107-112. doi: 10.1016/S0014-2999(02)02829-7.

Soares, M. B. P., Brustolin, D., Santos, L.A., Bellintani, M. C., Paiva, F.P., Ribeiro, Y.M., Tomassini, T. C. B. and Ribeiro Dos Santos, R. (2006). Physalins B, F and G, seco-steroids purified from Physalins angulata L., inhibit lymphocyte function and allogenic transplant rejection. International Immunopharmacology 6, 408-414. doi: 10.1016/j. intimp.2005.09.007.

Urbina, J. A. (2010). New insights in Chagas disease treatment. Drugs of the Future 35, 409-419. doi: 10.1358/dof.2010.035.05.1484391.

Urbina, J. A. and Docampo, R. (2003). Specific chemotherapy of Chagas disease: controversies and advances. Trends in Parasitology 19, 495-501. doi: 10.1016/j.pt.2003.09.001

Vanier-Santos, M. A. and De Castro, S. L. (2009). Electron microscopy in antiparasitic chemotherapy: a (close) view to a kill. Current Drug Targets $\mathbf{1 0}$, 246-260. doi: 10.2174/138945009787581168.

Veiga-Santos, P., Barrias, E.S., Santos, J.F.C., de Barros Moreira, T. L., de Carvalho, T. M., Urbina, J. A. and de Souza, W. (2012). Effects of amiodarone and posaconazole on the growth and ultrastructure of Trypanosoma cruzi. International fournal of Antimicrobial Agents 40, 61-71. doi: 10.1016/j.ijantimicag.2012.03.009.

Vieira, N.C., Espíndola, L.S., Santana, J. M., Veras, M. L., Pessoa, O.D., Pinheiro, S.M., de Araújo, R.M., Lima, M. A. and Silveira, E. R. (2008). Trypanocidal activity of a new pterocarpan and other secondary metabolites of plants from Northeastern Brazil flora. Bioorganic Medicinal Chemistry 16, 1676-1682. doi: 10.1016/j.bmc. 2007.11.027.

Wu, S. Y., Leu, Y. L. and Chang, Y.L. (2012). Physalin F induces cell apoptosis in human renal carcinoma cells by targeting NF-kappaB and generating reactive oxygen species. PLoS ONE 7, e40727. doi: 10.1371/ journal.pone.0040727. 